\title{
Micro-Scale Abrasive Wear Testing of CrN Duplex PVD Coating on Pre-Nitrided Tool Steel
}

\author{
Rafael David Mercado-Solis ${ }^{a}$, José Guadalupe Mata-Maldonado ${ }^{a}$, Miguel Angel Quinones-Salinas ${ }^{a}$ \\ Eduardo Rodriguez-de-Anda ${ }^{b}$, Rumualdo Servín-Castañeda ${ }^{c}$ \\ ${ }^{a}$ Universidad Autónoma de Nuevo León, San Nicolás de los Garza, Nuevo León, 66455, México \\ ${ }^{b}$ Universidad de Guadalajara, Guadalajara, Jalisco, 44430, México \\ ${ }^{c}$ Universidad Autónoma de Coahuila, Monclova, Coahuila, 25280, México
}

Received: October 07, 2016; Revised: May 03, 2017; Accepted: May 22, 2017

\begin{abstract}
Specific wear rates were calculated from a series of micro-scale abrasive tests by means of the calotte-grinding method. The tested material was a $\mathrm{CrN}$ coating deposited by arc evaporation on ionnitrided AISI H13 steel. Characterizations included: phase analysis, chemical composition, metallography, microhardness, micro-scratch resistance and nano-indentation hardness. On wear testing, the counter body was a $30 \mathrm{~mm}$ diameter steel ball rotating at a tangential speed of $9.42 \mathrm{~m} / \mathrm{min}$ and normal load of $0.54 \mathrm{~N}$. The abrasive was a mono-crystalline diamond micro abrasive paste, 1 micrometer grit. Wear volumes were calculated by measuring the wear scars at various test intervals. In non-perforating tests, Archard's wear equation was directly employed for calculating coating wear rate as the slope of the linear least square data fit. In perforating tests, Allsopp's method was employed for the simultaneous determination of coating and substrate wear rates, from the slope and intercept values of the linear least square data fit. Coating specific wear rate values obtained from both non-perforating and perforating tests were very consistent, with a relative difference within $6 \%$. Relative errors in specific wear rate values were estimated to be of the order of 0.05 for the coating and 0.2 for the substrate.
\end{abstract}

Keywords: Micro-scale abrasion, duplex surface treatment, specific wear rate, calotte grinding method, PVD coating, ion nitriding

\section{Introduction}

In surface engineering, the term duplex treatment refers to the sequential application of two surface modification technologies with the aim of producing a composite surface of such combined properties that are not obtainable through any of the individual technologies ${ }^{1}$. One type of duplex treatment of great technological importance is the process combination of atomic diffusion hardening followed by the deposition of a thin hard coating (oftentimes a nitride-type compound). More specifically, PVD coating of nitrided steel substrates is perhaps the most popular duplex treatment technology currently in use ${ }^{2-6}$. Duplex surface treatments have found extensive use in tribological applications because of their low friction and adequate balance between surface hardness, shear stress resistance, fracture toughness and load bearing capacity $^{7-9}$. In addition, due to their chemical inertness, PVD coatings are very well suited for resisting corrosion ${ }^{10-14}$. Some typical application examples of duplex surface treatments may be found in forming dies, casting molds, cutting tools and prosthetic implants ${ }^{15-20}$. Abrasive wear resistance is a key aspect in duplex-treated surfaces. However, since PVD coating thickness is only about a few micrometers and the abrasive particles may be even smaller, the term micro-scale

* e-mail: rafael.mercadosl@uanl.edu.mx abrasive wear better describe the abrasion of thin coatings, thus distinguishing it from bulk ('macro-scale') abrasive wear $^{21-23}$. Despite the advantages of duplex treatments in terms of wear and corrosion resistance, fracture toughness is usually compromised. Brittleness may lead to premature failure due to cracking, spalling or delamination. Therefore, a thorough optimization of the duplex treatment parameters along with extensive characterizations should always be performed in order to achieve the optimal combination of properties in service. These characterizations shall include microstructural analyses ${ }^{24-26}$, hardness, adhesion, toughness, wear resistance, etc. ${ }^{27-32}$. Chromium nitride (CrN) PVD coatings are extensively used in a wide range of engineering applications involving friction and wear. However, most of the studies reported in the literature have been performed assessing the macro-scale wear characteristics of this coating. The aim of this work was to assess the micro-scale wear behavior of a CrN PVD coating deposited on ion-nitrided AISI H13 tool steel (duplex treatment).

The calotte-grinding method, which is widely employed for coating thickness measurements ${ }^{33}$, also constitutes the basis for micro-scale abrasive wear testing. This method relies on the production of well defined calotte-shaped wear scars and their subsequent measurement for volume loss calculations. The testing principle is shown schematically in figure 1a, where a hard steel ball spins against a coated surface under 
a steady rotational speed transmitted via a driving shaft. A micro-abrasive particle suspension is dosed on the ball and drawn inside the contact, resulting in the progressive removal of the coating. The wear scars exhibit a large degree of conformity to the geometry of the ball (i.e. fully imposed shape). In other words, it is assumed that the shape of the ball is perfectly "copied" by the surface as the former may very effectively occupy the volume that is removed from the latter during wear. Under these conditions, the total wear volume $V_{T}$ may be estimated from the radius of the rotating ball $R$ and either the produced calotte diameter $D$ or its depth $h$ as:

$$
\begin{aligned}
& V_{T}=\frac{\pi}{64 R} D^{4} \\
& V_{T}=\pi h^{2} R
\end{aligned}
$$

Where $h$ may be approximated as:

$$
h=R-\sqrt{R^{2}-\frac{D^{2}}{4}}
$$

In the practice, however, diameter measurements are preferred over depth measurements for volume calculations because they are more easily performed using a standard optical microscope.

There are two types of micro-scale abrasion tests: nonperforating and perforating; the main difference being the extent of ball penetration with respect to coating thickness. In a non-perforating test, the ball does not penetrate into the substrate, thus, only coating removal occurs and the wear scar is accommodated entirely within the coating. Therefore, the direct usage of equations 1 and 2 is adequate for the determination of the wear volumes in non-perforating tests. However, in very thin and/or very fast wearing coatings, the ball may perforate the coating after only a few rotations. Thus, a composite contact occurs as the total wear volume is accommodated partly in the coating and partly in the substrate, as shown in figure $1 \mathrm{~b}$. In perforating tests, the substrate calotte wear volume $V_{S}$ may be estimated from equation 1 as a function of the inner diameter $d$ as:

$$
V_{S}=\frac{\pi}{64 R} d^{4}
$$

Thus, the coating wear volume $V_{C}$ may be calculated by combining equations 1 and 4 as follows:

$$
V_{C}=V_{T}-V_{S}=\frac{\pi}{64 R}\left(D^{4}-d^{4}\right)
$$

In most cases, the inner diameter is better defined and more accurately measured than the outer diameter. Therefore, the use of the inner diameter and the coating thickness $t$ instead of the outer diameter is usually preferred for calculating $V_{C}$ :

$$
V_{C}=\frac{\pi t}{4}\left(d^{2}-4 R t\right)
$$

Where $t$ may be derived from the following expression ${ }^{33}$ :

$$
t=\left[R^{2}-\left(\frac{d}{2}\right)^{2}\right]^{1 / 2}-\left[R^{2}-\left(\frac{D}{2}\right)^{2}\right]^{1 / 2}
$$

In non-perforating tests, the well-known Archard's wear equation may be directly applied to relate the volume of coating material removed $V_{c}$ to the product of the normal force $N$ and sliding distance $S$ :

$$
V_{C}=k_{C} S N
$$

Where $k_{C}$ is the coating specific wear rate.

Rutherford and Hutchings ${ }^{22}$ proposed the fundamental wear equation for a single set of data obtained from perforating tests, taking into account the composite contact:

$$
S N=\frac{V_{S}}{k_{S}}+\frac{V_{C}}{k_{C}}
$$

Where $k_{S}$ is the substrate specific wear rate.

According to Allsopp ${ }^{34}$, equation 9 may be rewritten in the form of a straight line $(y=m x+b)$ to allow the simultaneous

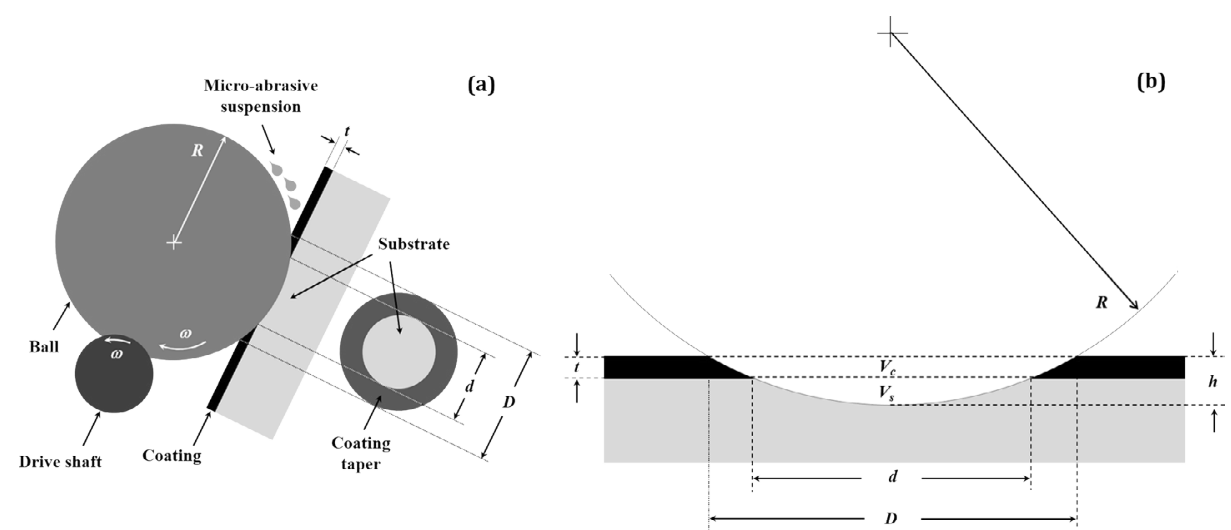

Figure 1. (a) Schematic representation of micro-scale abrasion tests. (b) Cross-section view and definition of volumes related to parameters $d, D, R, h$ and $t$. 
determination of $k_{C}$ and $k_{S}$ by linear least square fit from a single set of perforated tests data; the slope being $1 / k_{S}$ and the intercept $1 / k_{C}$. Thus, dividing equation 9 by $V_{C}$ we obtain:

$$
\frac{S N}{V_{C}}=\frac{1}{k_{S}} \frac{V_{S}}{V_{C}}+\frac{1}{k_{C}}
$$

Any measurement errors in $d, D, h$ and $t$ will evidently propagate into the values of $k_{C}$ and $k_{S}$. Kusano et.al. ${ }^{35}$ presented a comprehensive analysis of the influence of measurement errors on the reliability of the calculated wear rates. Evidently, as the relative measurement errors in $d$ and $t$ decrease, the relative errors in both $k_{C}$ and $k_{S}$ decrease. In addition, it was shown that as the ratio $k_{C} / k_{S}$ and/or the dimensionless parameter $d^{2} / R t$ decrease, then the relative error in $k_{C}$ decreases but that in $k_{S}$ increases. The parameter $d^{2} / R t$ is proportional to the ratio $(h-t) / t$, i.e. the extent of substrate penetration depth with respect to coating thickness.

\section{Testing Apparatus}

A commercial micro-scale abrasive wear testing device, denominated 'kaloMAX NT II', was employed in this study (Figure 2). This apparatus allows testing under the freerotating ball configuration, in which the ball leans freely against the test sample at a $60^{\circ}$ angle while being supported by two rubber rings at both sides of a V-shaped groove in the shaft. In this way, the ball's own weight produces the contact pressure against the sample. As the shaft rotates, slippage between the ball and the rubber rings is minimized due to the high friction of the contact, while relative motion between the ball and the sample is effectively introduced. In the device, the sample is clamped to a vice that is attached to an $\mathrm{X}-\mathrm{Y}$ compound stage by adjustment pins. When the wear scar is measured, the entire vice may be removed with the sample in place and put under the microscope. If a test will resume on the same calotte for longer sliding distances, the vice may be installed on the adjustment pins, allowing exact repositioning of the ball for continued testing. A tactile control panel allows the user to input, save and modify the desired testing parameters which include: grinding speeds between 1.4 and $55.8 \mathrm{~m} / \mathrm{min}$, shaft rotational speed from 30 to $500 \mathrm{rpm}$, number of shaft revolutions from 20 to 15,000 , grinding distance from 1.2 to $870 \mathrm{~m}$ and ball diameters from 12 to $40 \mathrm{~mm}$. The micro-abrasive suspension may be delivered either manually using a pipette or automatically by means of a dosage system consisting of a syringe attached to an air pump. Typically, only one drop (approximately $35 \mathrm{mg}$ ) of micro-abrasive suspension is required at the beginning of each test. Alternatively, a small quantity of metallographic grade crystalline micro-abrasive diamond paste may be smeared on the ball before starting a test.

\section{Materials}

Round plates $(\varnothing 30 \times 10 \mathrm{~mm})$ made from AISI H13 hotwork tool steel were employed as the substrate material in this study. The chemical composition of the steel, obtained through X-ray fluorescence, is presented in table 1. Prior to surface modifications, the substrates were vacuum heat treated by austenitizing, quenched and double tempered to hardness $46 \mathrm{HRC}$, followed by surface reconditioning by grinding and cleaning. The surface modifications consisted in the production of a $\mathrm{CrN}$ coating structure via a duplex treatment (ion nitriding + PVD) in discontinuous cycles. Comprehensive details of the duplex treatment process parameters employed in this study are presented in table 2. Process 1 corresponds to the ion nitriding stage, process 2 was an intermediate step where the substrates were polished and cleaned to produce a fresh metallic surface to enhance coating adhesion and process 3 was the PVD coating deposition stage itself. The test balls $(\varnothing 30 \mathrm{~mm}, 110$ grams $)$
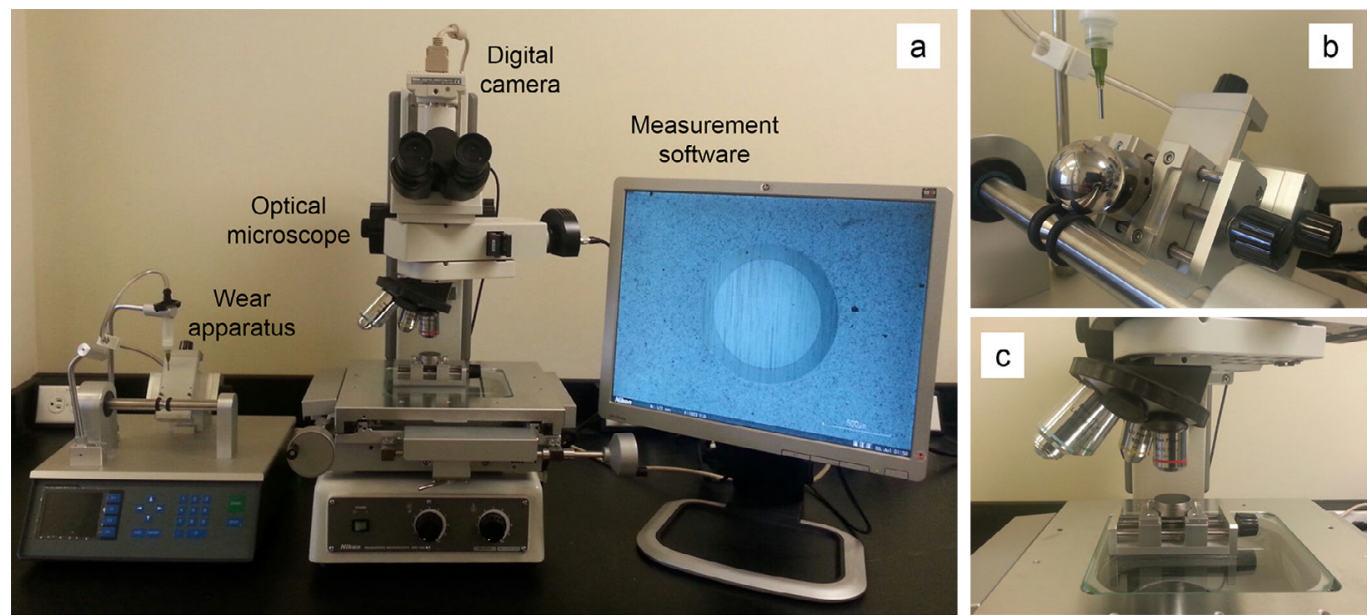

Figure 2. (a) General view of the micro-scale abrasion testing equipment. (b) Close-up of the experimental setup. (c) Sample placed under the optical microscope. 
Table 1. Chemical composition analyses of the AISI H13 tool steel substrates (wt.\%, balance Fe).

\begin{tabular}{cccccc}
\hline $\mathrm{Cr}$ & $\mathrm{Mo}$ & $\mathrm{V}$ & $\mathrm{C}$ & $\mathrm{Si}$ & $\mathrm{Mn}$ \\
\hline 5.3 & 1.3 & 0.9 & 0.39 & 1.0 & 0.4 \\
\hline
\end{tabular}

Table 2. Duplex treatment process parameters for surface modifications.

\begin{tabular}{|c|c|c|c|c|c|c|c|}
\hline & Process & Temp. $\left({ }^{\circ} \mathrm{C}\right)$ & $\begin{array}{c}\text { Pressure } \\
\text { (mbar) }\end{array}$ & Ubias (V) & $\begin{array}{l}\text { Current (A) X } \\
\text { No. of sources }\end{array}$ & $\begin{array}{l}\text { Time } \\
\text { (min.) }\end{array}$ & $\begin{array}{l}\text { Atmosphere } \\
\text { (vol.\%) }\end{array}$ \\
\hline \multirow{3}{*}{1} & Etching & 200 & $5 \times 10^{-3}$ & -350 & $80 \times 1$ & 15 & $100 \% \mathrm{Ar}$ \\
\hline & Preheating & $200-520$ & 2.5 & $(-300 /-800)$ & - & 60 & $20 \% \mathrm{Ar}, 80 \% \mathrm{H}_{2}$ \\
\hline & Nitriding & 520 & 4.3 & -600 & - & 420 & $10 \% \mathrm{~N}_{2}, 90 \% \mathrm{H}_{2}$ \\
\hline \multirow{2}{*}{2} & Surface polishing & & & & & & \\
\hline & Chemical cleaning & & & & & & \\
\hline \multirow{2}{*}{3} & Etching (ion bombardment) & 450 & $2 \times 10^{-5}$ & -900 & $80 \times 5$ & 15 & $100 \% \mathrm{Ar}$ \\
\hline & $\mathrm{CrN}$ coating deposition & 250 & $3.5 \times 10^{-2}$ & -200 & $70 \times 5$ & 150 & $100 \% \mathrm{~N}_{2}$ \\
\hline
\end{tabular}

were made from hardened steel $100 \mathrm{Cr} 6$ for rolling bearings (AISI 52100 equivalent), in compliance to ISO $3290-1^{36}$ for finish requirements.

\section{Experimental procedure}

\subsection{Materials characterizations}

Samples from the ion-nitrided substrates after process 2 were subsequently characterized by optical metallography, GDOES elemental depth profiling, Vickers microhardness depth profiles and X-ray diffraction (XRD). Duplex-treated samples obtained after process 3 were characterized by EDS chemical composition analysis, XRD, micro-scratch resistance and nano-indentation. All XRD analyses were performed for the purpose of phase constitution identification using a Philips PW1710 X-ray diffractometer with Cobalt-K alpha radiation. Measurements were conducted using a scanning step of $0.02^{\circ}$ for diffraction angles $(2 \theta)$ from $30^{\circ}$ to $120^{\circ}$ for the ion-nitrided substrate and from $30^{\circ}$ to $105^{\circ}$ for the CrN PVD coating. Micro-scratch resistance was measured using a CSEM Instruments Revetest scratch tester. The total scratch length was $15 \mathrm{~mm}$ and the indentation forced was progressively applied from $0.137 \mathrm{~N}$ to $150 \mathrm{~N}$ at constant loading rate $100 \mathrm{~N} / \mathrm{min}$ and travel speed $9.692 \mathrm{~mm} / \mathrm{min}$. The indenter was a diamond Rockwell C conical tip of radius 200 $\mu \mathrm{m}$ and $120^{\circ}$ angle apex. During the test, sensors signals for normal load, tangential load and acoustic emission were acquired as a function of scratch distance. Friction coefficient was calculated as the ratio of tangential to normal forces. Coating scratch resistance is expressed in terms of the magnitude of the indentation force at which various forms of coating failure are induced (critical loads), from cohesive to adhesive failure types: $L c_{1}$ cracking, $L c_{2}$ desquamation, $L c_{3}$ spallation and $L c_{4}$ delamination. Critical loads were determined from strong signal variations in combination with scratch observations using a microscope. Hardness and elastic modulus of the PVD coating were measured using a CSEM Instruments NHT nanohardness tester fitted with a Berkovich diamond tip. Coating thickness was measured beforehand via the calotte-grinding method, resulting in average thickness of $5.0 \mu \mathrm{m}$. In order to avoid the influence of the substrate during the indentation measurement, the tests were set to a maximum penetration depth of $500 \mathrm{~nm}$ ( $10 \%$ of coating thickness) at loading and unloading rates of $2 \mu \mathrm{m} / \mathrm{min}$, respectively. Arrays of twenty indentation measurements were performed, and the average indentation hardness and elastic modulus values were obtained.

\subsection{Tribological tests}

Micro-scale abrasion tests were performed using the kaloMAX NT II apparatus described in section 2. Prior to testing, a new steel ball $(\varnothing 30 \mathrm{~mm})$ was subjected to surface conditioning consisting of 300 revolutions against a flat ground steel coupon. This procedure was repeated in six different orientations of the steel ball, after which ten diameters were measured at random to ensure geometrical consistency. In order to remove dirt and debris after conditioning, ball and sample were ultrasonically cleaned for five minutes in petroleum ether, followed by rinsing and drying. After the ball is put into contact with the sample before the start of each test, $20 \mathrm{mg}$ of $1 \mu \mathrm{m}$ grit mono-crystalline diamond micro abrasive paste is smeared on the ball. The contact force between the ball and the sample is $0.54 \mathrm{~N}$ and it was considered constant throughout the test. The ball rotational speed was set to $100 \mathrm{rpm}$, equivalent to a relative sliding velocity of $9.42 \mathrm{~m} / \mathrm{min}$. The tests were performed under controlled ambient laboratory conditions, temperature 20 ${ }^{\circ} \mathrm{C}$ and relative humidity $50 \%$. A fresh surface location was chosen every time a new test was started. A total of thirteen tests of various sliding distances were conducted, from which the first five were non-perforating and the others were perforating. After each test, inner and outer calotte diameters were measured in 11 different orientations using an optical measuring microscope (Nikon MM-400/SL) fitted with a 
digital camera and imaging software (Figure 2). Median values of $d$ and $D$ were subsequently employed for wear volume calculations.

\section{Results and Discussion}

\subsection{Substrate characterization}

Figure 3 shows typical micrographs of the cross-section of the pre-nitrided substrate. As result of the ion-nitriding process, a diffusion layer about $70 \mu \mathrm{m}$ deep was developed (Figure 3a) and no compound -white- layers were formed. The contrast between the nitride layer and the base steel was achieved by chemical etching using a $4 \%$ Nital reagent. A transition zone between the diffusion layer and the base steel is clearly seen in the microstructure as nitrogen concentration decreases with depth. This was further confirmed by the elemental depth profiling analysis performed using GDOES. In this sense, figure 4 demonstrates that the nitrogen mass concentration at the surface was approximately $4 \%$ and decreased rapidly to $1.5 \%$ at a depth of about $10 \mu \mathrm{m}$. Between 10 and $70 \mu \mathrm{m}$, nitrogen concentration decreased steadily to a value of $1 \%$ and then decreased rapidly to very low concentration levels beyond $90 \mu \mathrm{m}$ in depth. The higher magnification micrograph of figure $3 b$ (corresponding to the dashed box of figure $3 a$ ) confirmed that no iron nitrides were developed within the diffusion layer as a result of the nitriding process. When present, iron nitrides are readily identified as stringer-like phases that extend in the form of a continuous network along the grains within the nitrided layer. On the one hand, the presence of compound (white) layers has a negative effect on PVD coating adhesion and, on the other hand, iron nitride formation promotes brittleness and lowers the mechanical strength of the nitrided microstructure. Thus, the avoidance of these undesirable microstructural phases was achieved by extensive research on the optimization of the nitriding parameters, prior to this work.

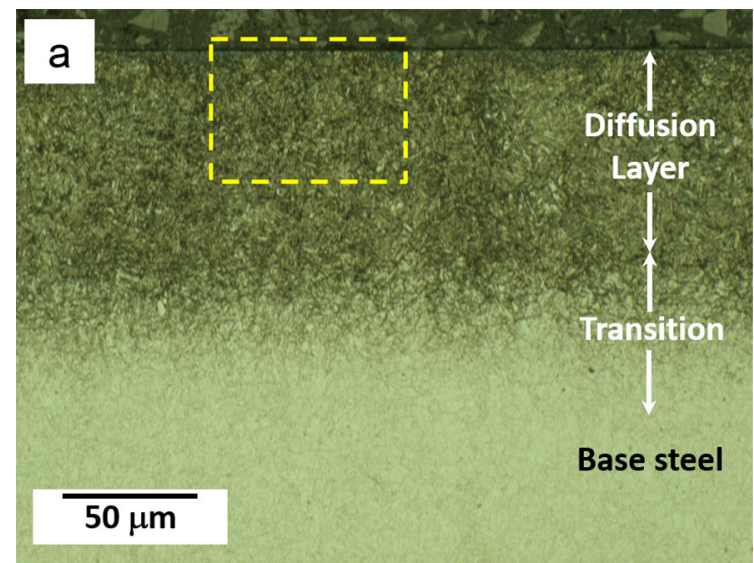

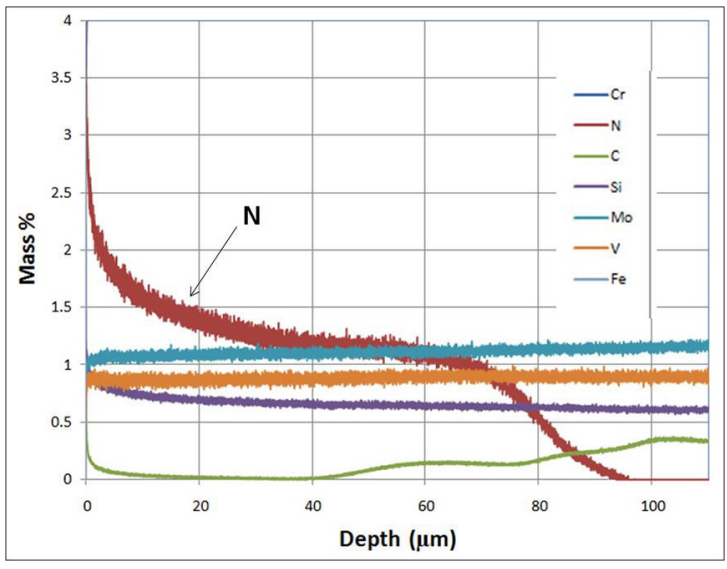

Figure 4. Results obtained from the GDOES elemental depth profile concentration analysis of the pre-nitrided steel substrate.

The microhardness depth profile of the pre-nitrided substrate is presented in figure 5. As expected, maximum hardness $\left(\sim 750 \mathrm{HV}_{0.5}\right)$ was measured near the surface. As nitrogen concentration decreased with depth, so did the average hardness of the diffusion layer. At depths between 100 and $150 \mu \mathrm{m}$, hardness decreased progressively in the transition zone between the diffusion layer and the base steel. From $200 \mu \mathrm{m}$ onwards, the hardness remained unchanged at average values of approximately $460 \mathrm{HV}_{0.5}$, which corresponds to the hardness of the quenched and tempered tool steel substrate (48 HRC).

Figure 6 shows the X-ray diffraction patterns of the ion-nitrided tool steel substrate. Based on the analysis, the dominant phase in the diffusion layer was the $\alpha-\mathrm{Fe}(\mathrm{N})$ phase along with some very limited amounts of the $\varepsilon-\mathrm{Fe}_{2-3} \mathrm{~N}$ phase. The $\gamma$ ' phase was not at all present in the substrate sample. These findings confirm the metallographic observations in the sense that no compound -white- layer or iron nitrides were developed as a result of the relatively low concentration of nitrogen in the ion-nitriding process gas mixture $\left(10 \% \mathrm{~N}_{2}\right)$.

Figure 3. (a) Optical micrograph the cross-section of the pre-nitrided steel substrate. (b) Microstructure of the highlighted region in (a). 


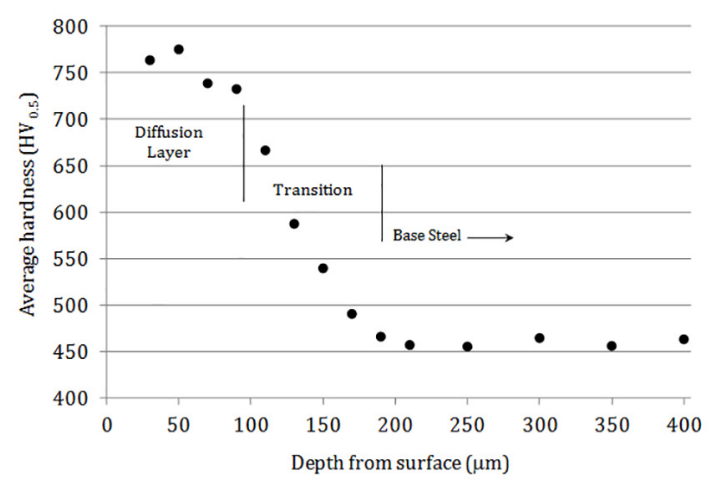

Figure 5. Microhardness depth profile of pre-nitrided steel substrate.

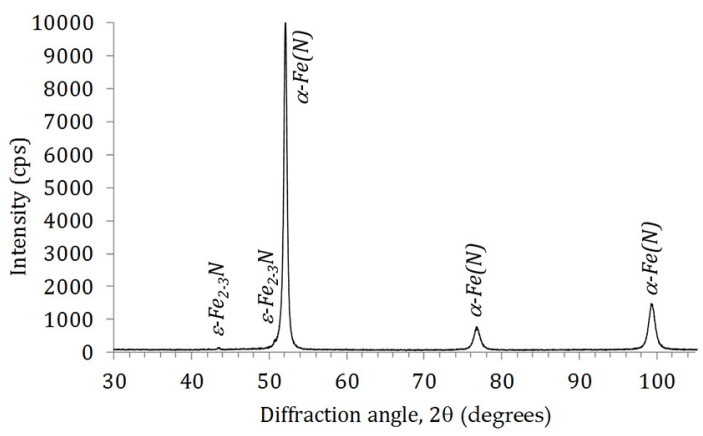

Figure 6. X-ray diffraction patterns of the ion-nitrided tool steel substrate.

\subsection{Coating characterization}

Figure 7 shows the results of the chemical composition analyses performed energy dispersive X-ray spectroscopy (EDS) on a metallographic micro-polished cross-section of the duplex-treated sample. The results of a line scan across the coating and the pre-nitrided substrate are shown on the left, while the quantitative results of chemical composition by EDS within the red boxes are presented on the right of the figure. High concentrations of chromium and nitrogen are present in the coating, with atomic percent $17.47 \%$ for nitrogen and $82.53 \%$ for chromium. Iron, chromium and nitrogen were confirmed as the main elements present in the substrate.

X-ray diffraction patterns of the PVD coating revealed the characteristic peaks of chromium nitride phases $\mathrm{CrN}$ and $\mathrm{Cr}_{2} \mathrm{~N}$, as shown in figure 8 . The $\alpha-\mathrm{Fe}(\mathrm{N})$ phase from the nitrided layer was detected in the spectra (as expected due to the influence of the substrate), but their relative intensities were much smaller than those in the uncoated substrate (Figure 6).

The results from the scratch tests of the duplex-treated sample are presented in figure 9. Critical loads were established as $28 \mathrm{~N}\left(L c_{1}\right), 62 \mathrm{~N}\left(L c_{2}\right), 78 \mathrm{~N}\left(L c_{3}\right)$ and $107 \mathrm{~N}$ $\left(L c_{4}\right)$, corresponding to scratch lengths $3.0 \mathrm{~mm}, 6.5 \mathrm{~mm}$, $7.7 \mathrm{~mm}$ and $10.8 \mathrm{~mm}$, respectively. At $L c_{l}$, the first acoustic emission signals were detected, corresponding to the onset

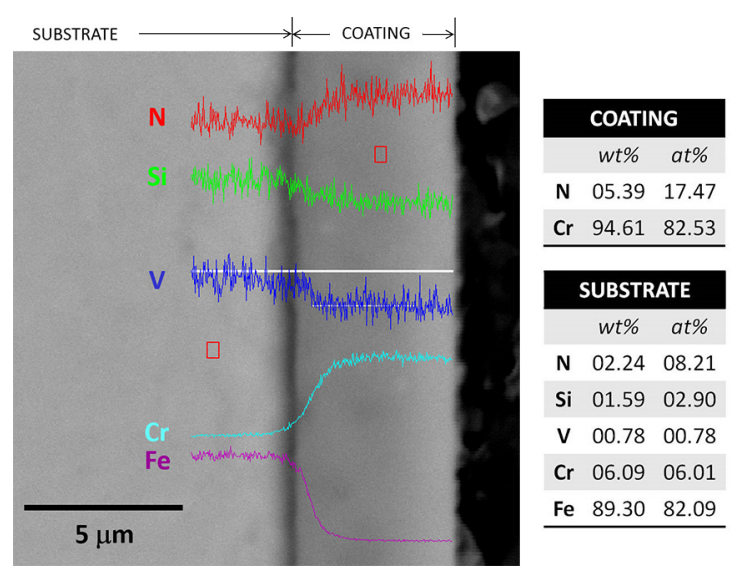

Figure 7. Cross-sectional EDS elemental analysis of the duplextreated sample.

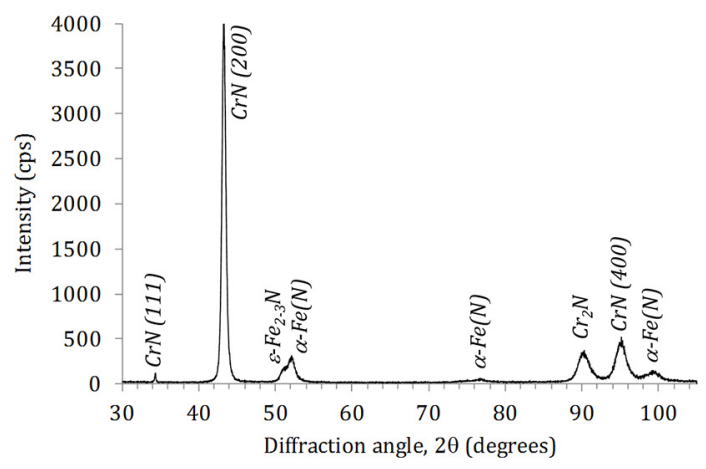

Figure 8. X-ray diffraction patterns of the CrN PVD coating.
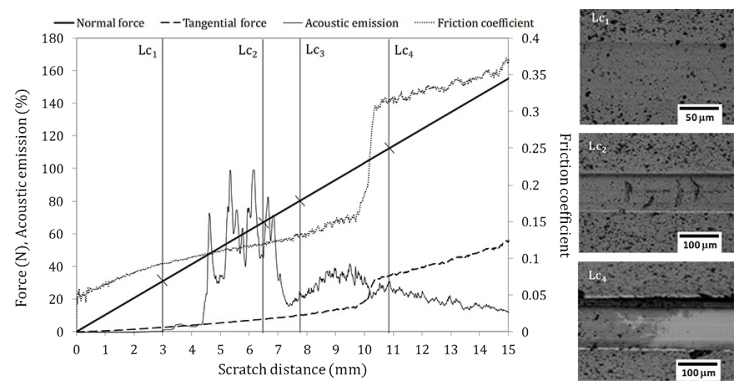

Figure 9. Scratch test results of the duplex-treated sample.

of coating failure by micro cracking. At $L c_{2}$, strong acoustic emission signals were generated due to coating desquamation and subsequent spallation at $L c_{3}$. Finally, a sharp transition in the value of friction coefficient was measured between scratch distances 10 and $11 \mathrm{~mm}$. This is attributed to a modification in the contact nature between the two sliding bodies. Up to this point, the contact had taken place between the diamond tip and the coating. This is the case until the tip penetration depth equals the coating thickness, from which a compound contact between the tip and the coating/substrate interface occurs resulting in a marked increase in friction. At $L c_{4}$, since full delamination of the coating has occurred and the 
normal load is now fully supported by the substrate, a steady increase in friction coefficient is again observed due to the contact between the tip and the substrate. Nano-indentation tests of the PVD coating resulted in average indentation hardness of $18.32 \pm 2.8 \mathrm{GPa}$ and elastic modulus $287 \pm 16$ $\mathrm{GPa}$. These results are consistent with values reported in the literature ${ }^{37-39}$.

\subsection{Tribological tests}

Micrographs of typical wear scars are presented in figure 10. In general, both the inner and outer diameters exhibited well defined edges, particularly at longer sliding distances. It is evident that the dominant wear mechanism was micro-abrasion as an array of fine micro grooves oriented in the direction of ball rotation was clearly observed inside the wear scars. The spacing between the grooves was approximately equal to the average size of the grit of the abrasive particles $(1 \mu \mathrm{m})$ that are continuously being drawn within the contact by the rotating ball. No evidence of lack of adhesion was observed in coating/substrate interface and the coating taper exhibited a large degree of continuity (i.e. coating failure by cracking, pitting, etc. was not present). The experimental results of the micro-scale abrasion tests are summarized in table 3. In non-perforating tests, $V_{C}$ was calculated using equation
1, while in perforating tests, $V_{S}$ and $V_{C}$ were calculated via equations 4 and 5 , respectively. The total penetration depth $h$ was calculated from equation 3 which employs both the ball radius $R$ and the outer calotte diameter $D$. These results are presented graphically in figure 11 as plots of $S N$ versus: diameters size (fig. 11a), wear volumes (fig. 11b) and total penetration depth (fig. 11c). Very small increments in sliding distances allowed performing five measurements of the coating diameter $D$ prior to its perforation. The onset of composite contact took place between the fifth and the sixth measurement, once the ball penetration depth had exceeded the coating thickness of $5 \mu \mathrm{m}$. The approximate transition point between the non-perforating and the perforating contact regimes is indicated in figures $11 \mathrm{a}-\mathrm{c}$ by the vertical line at $S N \approx 3.511 \mathrm{mN}$. It can be clearly observed from figure $11 \mathrm{~b}$ that, once coating perforation has taken place, the rate of increase in substrate wear volume becomes larger than that of the coating because it is much softer; thus resulting in a faster wearing material, as discussed by Ramahlo ${ }^{40}$. At $21.069<S N<24.581$ both the coating and the substrate wear volumes are of equal magnitude; therefore, each one accounts for exactly one-half of the total wear volume, $V_{T}$. From this point onwards, the substrate wear volume becomes more significant than the coating wear volume. In the non-perforating test interval, coating volume wear $V$
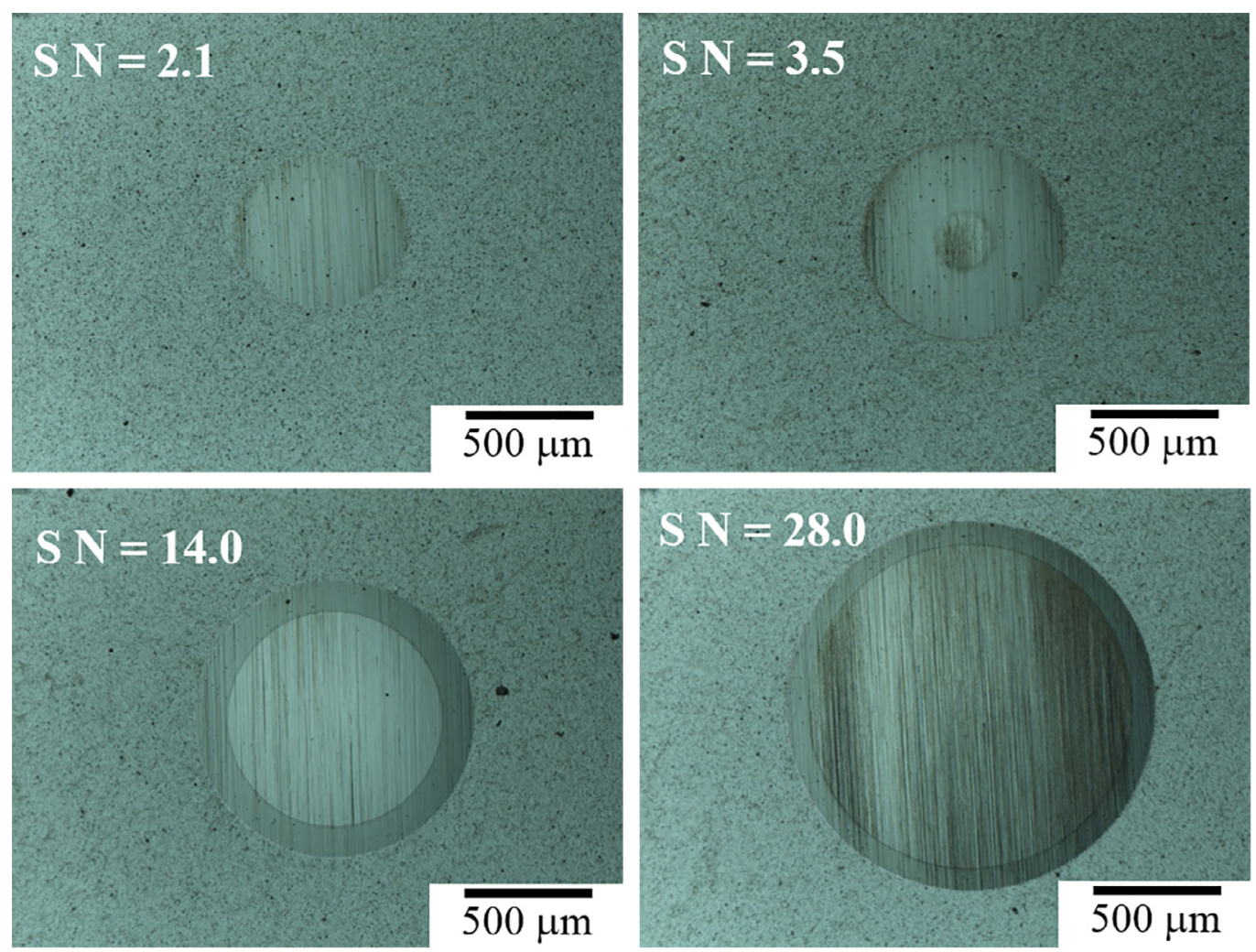

Figure 10. Micrographs of the produced wear scars after various test intervals. 
Table 3. Summary of micro-abrasive wear measurements: ball radius $15 \mathrm{~mm}, N=0.54 \mathrm{~N}$.

\begin{tabular}{ccccccc}
\hline $\begin{array}{c}\text { Sliding distance, } \\
S(\mathrm{~m})\end{array}$ & $S N(\mathrm{~m} \cdot \mathrm{N})$ & $\begin{array}{c}\text { Outer diameter, } \\
D\left(\mathrm{x} 10^{-3} \mathrm{~mm}\right)\end{array}$ & $\begin{array}{c}\text { Inner diameter, } \\
d\left(\mathrm{x} 10^{-3} \mathrm{~mm}\right)\end{array}$ & $\begin{array}{c}\text { Depth, } h \\
\left(\mathrm{x} 10^{-3} \mathrm{~mm}\right)\end{array}$ & $\begin{array}{c}\text { Coating volume, } \\
V_{C}\left(\mathrm{x} 10^{-3} \mathrm{~mm}^{3}\right)\end{array}$ & $\begin{array}{c}\text { Substrate } \\
\text { volume, } V_{S} \\
\left(\mathrm{x} 10^{-3} \mathrm{~mm}^{3}\right)\end{array}$ \\
\hline 0.650 & 0.351 & 295.29 & - & 0.72 & 0.024 & - \\
1.300 & 0.702 & 542.25 & - & 2.45 & 0.282 & - \\
2.601 & 1.404 & 621.95 & - & 3.22 & 0.489 & - \\
3.901 & 2.106 & 697.98 & - & 4.06 & 0.776 & - \\
5.202 & 2.809 & 748.42 & - & 4.67 & 1.026 & 0.0045 \\
6.503 & 3.511 & 800.37 & 192.78 & 5.34 & 1.338 & 0.490 \\
13.006 & 7.023 & 997.55 & 622.33 & 8.29 & 2.749 & 1.219 \\
19.509 & 10.534 & 1105.98 & 781.32 & 10.20 & 3.676 & 2.514 \\
26.012 & 14.046 & 1203.41 & 936.23 & 12.07 & 4.349 & 3.697 \\
32.515 & 17.558 & 1286.15 & 1031.02 & 13.79 & 5.256 & 5.663 \\
39.018 & 21.069 & 1375.74 & 1146.96 & 15.78 & 6.059 & 8.991 \\
45.521 & 24.581 & 1485.02 & 1287.47 & 18.39 & 6.923 & 7.393 \\
52.024 & 28.092 & 1525.17 & 1332.39 & 19.40 & & 10.313 \\
\hline
\end{tabular}
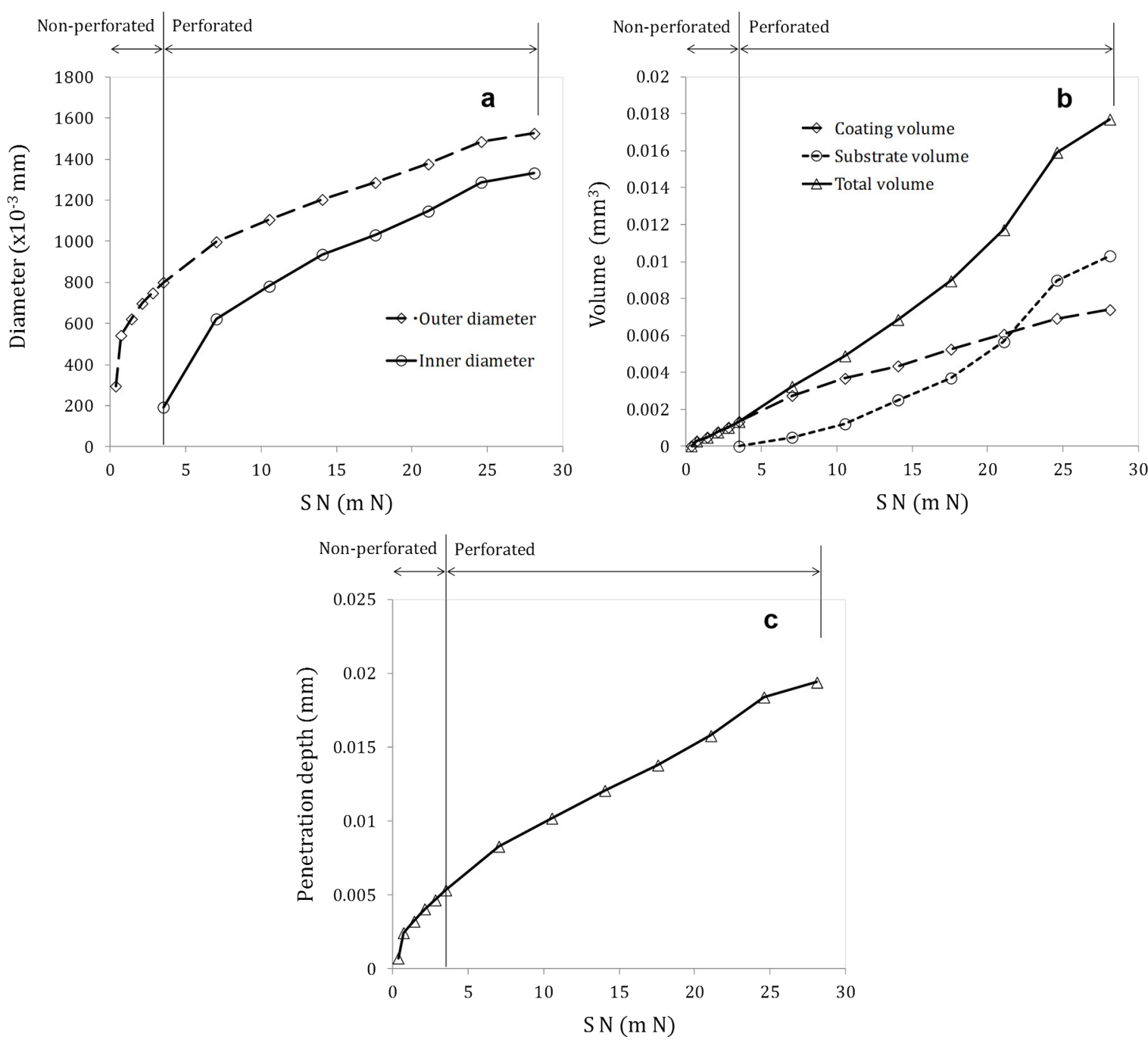

Figure 11. Plots of SN versus: (a) diameter, (b) volume and (c) penetration depth. 


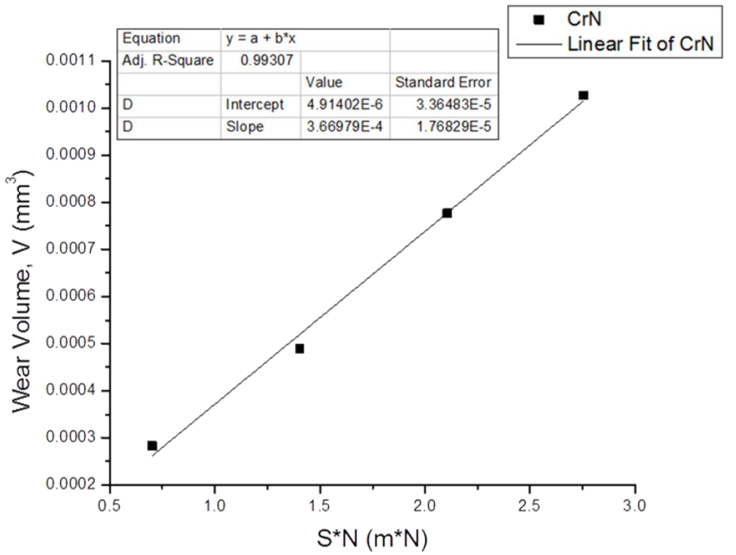

Figure 12. $S N$ versus $V_{C}$ for $k_{\mathrm{C}}$ determination in the non-perforating test interval.

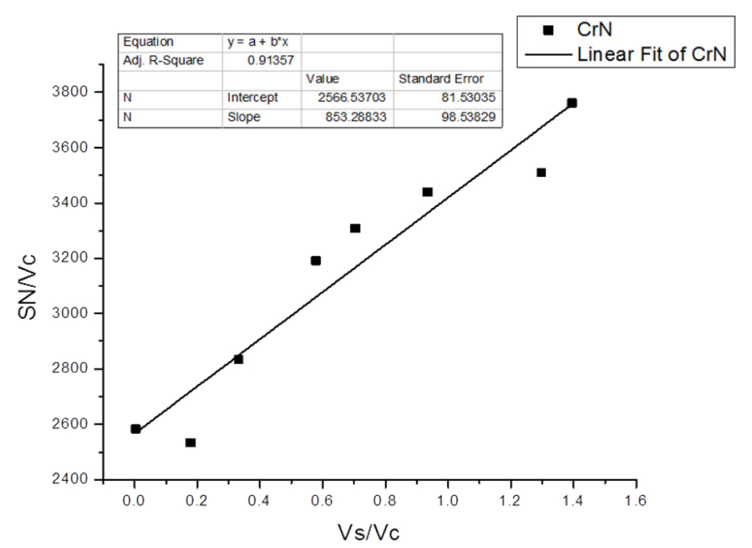

Figure 13. $V_{S} / V_{C}$ versus $S N / V_{C}$ for simultaneous determination of $k_{\mathrm{C}}$ and $k_{\mathrm{S}}$ in the perforating test interval.

may be directly related to the product of the normal force $N$ and sliding distance $S$, the constant of proportionality being the coating specific wear rate $k_{C}$ (equation 8 ). The results of $S N$ versus $V_{C}$ for the non-perforating interval are presented in figure 12. The least-squares regression line of best fit of the data points is also included in the graph. The linear regression analysis resulted in a coefficient of determination $\mathrm{R}^{2}=0.99307$ and slope $3.66979 \mathrm{E}^{-4} \mathrm{~mm}^{3} / \mathrm{mN}$, which is the coating specific wear rate, $k_{C}$. Similarly, for the perforated interval (composite contact), it is possible to simultaneously determine $k_{C}$ and $k_{S}$ by linear least square fit of a single set of perforated tests data; the slope being $1 /$ $k_{S}$ and the intercept $1 / k_{C}$ (equation 10). The results of $V_{S}$ $V_{C}$ versus $S N / V_{C}$ and the line of best fit of the data points in the perforating test interval are presented in figure 13. The least-square regression analysis yielded an $\mathrm{R}^{2}=0.91357$, intercept $1 / k_{C}=2566.53 \mathrm{mN} / \mathrm{mm}^{3}$ and slope $1 / k_{S}=853.28$ $\mathrm{mN} / \mathrm{mm}^{3}$; thus, $k_{C}=3.8963 \mathrm{E}^{-4} \mathrm{~mm}^{3} / \mathrm{mN}$ and $k_{S}=1.1719 \mathrm{E}^{-3}$ $\mathrm{mm}^{3} / \mathrm{mN}$. Therefore, the calculated coating specific wear rates in both the non-perforating and the perforating test intervals were very consistent, with a relative difference below $6 \%$. From these results, it is concluded that the nitride steel substrate wears at a specific rate which is three times faster than that of the CrN PVD coating. Finally, based on the reliability method proposed by Kusano et. al. ${ }^{35}$, for the typical magnitudes of measurement errors of $1 \%$ in inner calotte diameter and $5 \%$ in coating thickness, $d^{2} / R t=16$ and $\mathrm{k}_{C} / k_{S}=0.3324$, the estimated errors in specific wear rate of this study were 0.05 for the coating and 0.2 for the substrate.

\section{Conclusions}

Specific micro-scale abrasive wear rates of a $\mathrm{CrN}$ duplex coating deposited on pre-nitrided AISI H13 tool steel were calculated via the calotte grinding method in conjunction with Archard's and Allsopp's methods for wear data analysis. A remarkable consistency was found in both non-perforating and perforating tests, with a relative difference within $6 \%$. In the former, coating specific wear rate was $3.66979 \mathrm{E}^{-4} \mathrm{~mm}^{3 /}$ $\mathrm{mN}$, whereas in the later it was $3.8963 \mathrm{E}^{-4} \mathrm{~mm}^{3} / \mathrm{mN}$. Specific wear rate of the pre-nitrided steel substrate was estimated in the order of $1.1719 \mathrm{E}^{-3} \mathrm{~mm}^{3} / \mathrm{mN}$, i.e. three times greater than that of the coating. Coating adhesion to the substrate did not seem to have an effect on the wear behavior, whereas hardness is directly related to the wear characteristics of the duplex system. The results from this work shall be taken as valid for the particular tribo-system under study and may serve for reference purposes. Other results may be expected in other testing scenarios involving different materials, velocities, loads, type of abrasive, temperature, humidity, etc.

\section{Acknowledgements}

The authors wish to thank the following institutions for the support provided for conducting this work: Universidad Autonoma de Nuevo Leon, Universidad de Guadalajara and Consejo Nacional de Ciencia y Tecnología (CONACYTMexico). We also wish to acknowledge the collaboration of the scientific and technical staff from the Institute for Sustainable Technologies (ITeE-PIB) in Radom, Poland.

\section{References}

1. Bell T, Dong H, Sun Y. Realising the potential of duplex surface engineering. Tribology International. 1998;31(1-3):127-137. DOI: 10.1016/S0301-679X(98)00015-2

2. Mahboubi F, Fattah M. Duplex treatment of plasma nitriding and plasma oxidation of plain carbon steel. Vacuum. 2005;39(12):1-6. DOI: 10.1016/j.vacuum.2005.01.002

3. El-Hossary FM, Negm NZ, El-Rahman AMA, Hammad M. Duplex treatment of 304 AISI stainless steel using rf plasma nitriding and carbonitriding. Materials Science and Engineering: C. 2009;29(4):1167-1173. DOI: 10.1016/j.msec.2008.09.049

4. Ma S, Li Y, Xu K. The composite of nitirided steel of H13 and TiN coatings by plasma duplex treatment and the effect of pre-nitriding. Surface and Coatings Technology. 2001;137(23):116-121. DOI: 10.1016/S0257-8972(00)01073-2 
5. Rousseau AF, Partridge JG, Mayes ELH, Toton JT, Kracica $\mathrm{M}$, McCulloch DG, et al. Microstructural and tribological characterisation of a nitriding/TiAlN PVD coating duplex treatment applied to M2 high speed steel tools. Surface and Coatings Technology. 2015;272:403-408. DOI: 10.1016/j. surfcoat.2015.03.034

6. De Las Heras E, Egidi DA, Corengia P, Gonzalez-Santamaria D, Garcia-Luis A, Brizuela M, et al. Duplex surface treatment of an AISI 316L stainless steel; microstructure and tribological behavior. Surface and Coatings Technology. 2008;202(13):29452954. DOI: $10.1016 /$ j.surfcoat.2007.10.037

7. Pogrebnjak AD, Shumakova NI. Effect of 'duplex' treatment on changes of physical and mechanical properties of steel $(0.3$ wt\% C). Surface and Coatings Technology. 1999;122(2-3):183187. DOI: $10.1016 / \mathrm{S} 0257-8972(99) 00064-\mathrm{X}$

8. Walkowicz J, Smolik J, Tacikowski J. Optimization of nitirided case structure in composite layers created by duplex treatment on the basis of PVD coating adhesion measurement. Surface and Coatings Technology. 1999;116-119:370-379. DOI: 10.1016/ S0257-8972(99)00079-1

9. Mesa DH, Pinedo CE, Tschiptschin AP. Improvement of the cavitation erosion resistance of UNS S31803 stainless steel by duplex treatment. Surface and Coatings Technology. 2010;205(5):1552-1556. DOI: 10.1016/j.surfcoat.2010.10.014

10. Chen C, Li Q, Leng Y, Chen JY, Zhang PC, Bai B, et al. Improved hardness and corrosion resistance of iron by Ti/TiN multilayer coating and plasma nitriding duplex treatment. Surface and Coatings Technology. 2010;204(18-19):3082-3086, http:// dx.doi.org/10.1016/j.surfcoat.2010.03.017

11. Chala A, Nouveau C, Djouadi MA, Steyer P, Millet JP, Saied $\mathrm{C}$, et al. Effect of duplex treatments by plasma nitriding and triode sputtering on corrosion behaviour of 32CDV13 low alloy steel. Surface and Coatings Technology. 2006;200(2223):6568-6571. DOI: 10.1016/j.surfcoat.2005.11.036

12. Liscano S, Gil L, Leon OA, Cruz M, Staia MH. Corrosion performance of duplex treatments based on plasma nitriding and PAPVD TiAlN coating. Surface and Coatings Technology. 2006;201(7):4419-4423. DOI: 10.1016/j.surfcoat.2006.08.056

13. Mouri L, Mabille I, Fiaud C, Amouroux J, Catillon G, Gras R. Study of corrosion resistance and surface properties of carbon steel after a duplex plasma treatment. Thin Solid Films. 2001;398(1-2):153-160. DOI: 10.1016/S0040-6090(01)00875-6

14. Dong H, Sun Y, Bell T. Enhanced corrosion resistance of duplex coatings. Surface and Coatings Technology. 1997;90(1-2):91101. DOI: 10.1016/S0257-8972(96)03099-X

15. Walkowicz J, Smolik J, Miernik K, Bujak J. Duplex surface treatment of moulds for pressure casting of aluminium. Surface and Coatings Technology. 1997;93(1-3):453-464. DOI: 10.1016/ S0257-8972(97)00203-X

16. Soković M, Panjan P, Kirn R. Possibilities of improvement of dies casting tools with duplex treatment. Journal of Materials Processing Technology. 2004;157-158:613-616. DOI: 10.1016/j. jmatprotec.2004.07.145
17. Panjan P, Čekada M, Kirn R, Soković M. Improvement of die-casting tools with duplex treatment. Surface and Coatings Technology. 2004;180-181:561-565. DOI: 10.1016/j.surfcoat.2003.10.119

18. Navinšek B, Panjan P, Gorenjak F. Improvement of hot forging manufacturing with PVD and DUPLEX coatings. Surface and Coatings Technology. 2001;137(2-3):255-264. DOI: 10.1016/ S0257-8972(00)01115-4

19. Ortega-Saenz JA, Alvarez-Vera M, Hernandez-Rodriguez MAL Biotribological study of multilayer coated metal-on-metal hip prostheses in a hip joint simulator. Wear. 2013;301(1-2):234242. DOI: 10.1016/j.wear.2013.01.024

20. Gallegos-Cantú S, Hernandez-Rodriguez MAL, Garcia-Sanchez E, Juarez-Hernandez A, Hernandez-Sandoval J, Cue-Sampedro R. Tribological study of TiN monolayer and TiN/CrN (multilayer and superlattice) on Co-Cr alloy. Wear. 2015;330-331:439-447. DOI: 10.1016/j.wear.2015.02.010

21. Kassman A, Jacobson S, Erickson L, Hedenqvist P, Olsson M. A new test method for the intrinsic abrasion resistance of thin coatings. Surface and Coatings Technology. 1991;50(1):75-84. DOI: 10.1016/0257-8972(91)90196-4

22. Rutherford KL, Hutchings IM. A micro-abrasive wear test, with particular application to coated systems. Surface and Coatings Technology. 1996;79(1-3):231-239. DOI: 10.1016/02578972(95)02461-1

23. Rutherford K, Hutchings I. Theory and application of a microscale abrasive wear test. Journal of Testing and Evaluation. 1997;25(2):250-260. DOI: 10.1520/JTE11487J

24. Béger M, Jurči P, Grgač P, Mečiar S, Kusý M, Horník J. Cr $\mathrm{r}_{\mathrm{x}}$ coatings prepared by magnetron sputtering method. Kovové Materiály-Metallic Materials. 2013;51(1):1-10.

25. Zhao ZB, Rek ZU, Yalisove SM, Bilello JC. Phase formation and structure of magnetron sputtered chromium nitride films: in-situ and ex-situ studies. Surface and Coatings Technology. 2004;185(2-3):329-339. DOI: 10.1016/j.surfcoat.2003.12.026

26. Shah HN, Jayaganthan R, Kaur D, Chandra R. Influence of sputtering parameters and nitrogen on the microstructure of chromium nitride films deposited on steel substrate by directcurrent reactive magnetron sputtering. Thin Solid Films. 2010;518(20):5762-5768. DOI: 10.1016/j.tsf.2010.05.095

27. Lai FD, Wu JK. Structure, hardness and adhesion properties of $\mathrm{CrN}$ films deposited on nitride and nitrocarburized SKD 61 tool steels. Surface and Coatings Technology. 1997;88(13):183-189. DOI: 10.1016/S0257-8972(96)02864-2

28. Van Stappen M, Malliet B. Characterization of TiN coatings deposited on plasma nitrided tool steel surfaces. Materials Science and Engineering A. 1991;140:554-562. DOI: 10.1016/09215093(91)90478-6

29. Spies HJ, Höck K, Larisch B. Production and properties of duplex cases using a combination of nitriding and hardcoating. Härterei-Technische Mitteilungen - HTM. 1996;51(4):222-231, in German.

30. Jurči P. Cr-V ledeburitic cold-work tool steels. Materiali in Tehnologije. 2011;45(5):383-394. 
31. Jurči P, Hudáková M. Diffusion Boronizing of H11 Hot Work Took Steel. Journal of Materials Engineering and Performance. 2011;20(7):1180-1187. DOI: 10.1007/s11665-010-9750-x

32. Jurči P, Dlouhý I. Coating of Cr-V ledeburitic steel with $\mathrm{CrN}$ containing a small addition of Ag. Applied Surface Science. 2011;257(24):10581-10589. DOI: 10.1016/j.apsusc.2011.07.054

33. Quinones-Salinas MA, Mercado-Solis RD. A comparative study of three methods for measuring thickness of PVD hard coatings. International Journal of Surface Science and Engineering. 2015;9(6):493-509. DOI: 10.1504/IJSURFSE.2015.072831

34. Allsopp DN. Abrasive wear of bulk materials and hard coatings. [Ph.D. Thesis]. Cambridge: University of Cambridge; 1999.

35. Kusano K, Van Acker K, Hutchings IM. Methods of data analysis for the micro-scale abrasion test on coated substrates. Surface and Coatings Technology. 2004;183(2-3):312-327. DOI: $10.1016 /$ j.surfcoat.2003.10.010
36. International Organization for Standardization. ISO 3290-1: 2014 - Rolling bearings - Balls - Part 1: Steel balls. Geneva: International Organization for Standardization; 2014.

37. Ichimura $\mathrm{H}$, Ando I. Mechanical properties of arc-evaporated $\mathrm{CN}$ coatings: Part I - nanoindentation hardness and elastic modulus. Surface and Coatings Technology. 2001;145(1-3):88-93. DOI: 10.1016/S0257-8972(01)01290-7

38. Cunha L, Andritschky M, Pischow K, Wang Z. Microstructure of CrN coatings produced by PVD techniques. Thin Solid Films. 1999;355-356:465-471. DOI: 10.1016/S0040-6090(99)00552-0

39. Hogmark S, Jacobson S, Larsson M. Design and evaluation of tribological coatings. Wear. 2000;246(1-2):20-33. DOI: 10.1016/S0043-1648(00)00505-6

40. Ramalho A. Micro-scale abrasive wear of coated surfaces-prediction models. Surface and Coatings Technology. 2005;197(2-3):358366. DOI: 10.1016/j.surfcoat.2004.12.024 